\title{
The Obstacles that Parents Encountered when Taking Children to Psychological Clinic in Vietnam
}

DOI: https://doi.org/10.47175/rissj.v1i2.55

\section{| Nguyen Thi Dung |}

Lecturer of English, Binh

Thuan Province Vocational

College, Vietnam

nguyenthidung04111981bt@g

mail.com

\begin{abstract}
This study aimed to explore difficulties that parents faced when bringing their children to psychological examination in Vietnam through their life stories. The research participants included 5 fathers and 3 mothers having children diagnosed with autism. A preliminary interview prior to the study and in-depth interviews were carried out with their voluntariness. To collect and analyze the data, "Life Story Interview" list was implemented, data analysis phases of interpretative phenomenology was used in this study. As a result, key problems that parents met on this tough journey so that their children could be examined were (1) financial problems, (2) tiredness, and (3) unexpected behaviors of the children. Analyses showed that despite the challenges, parents tried their best in order to know exactly the name of their children's problem.

KEYWORDS

Interpretative phenomenology; diagnosis; autism; obstacles
\end{abstract}

\section{INTRODUCTION}

Autism Spectrum Disorders (ASD) is regarded as a severe neurodevelopmental disorder by American Psychiatric Association in 2013 whose basic impairments are the delay and deviance in social interaction, in communication and language, as well as in restricted interests and repetitive behaviors (Faja \& Dawson, 2006). Autistic children's parents are extremely anxious, and tired when looking for a diagnosis for their children (Singer, 2010). Often do these parents experience unexpected stress and necessary consultation (NeelyBarnes et al., 2011). Furthermore, parents experience noteworthy physical, and economic burdens during the time of raising the autistic children (Altiere and von Kluge, 2009).

While lives of these families in Western countries have been explored in many studies such as those in the United States (Phelps, Hodgson et al. 2009), in the United Kingdom (Howlin, Goode et al. 2004), those in non-Western nations have not been largely examined ( $\mathrm{Vu}, 2014)$. In Vietnam, there is still limited in ASD understanding (CLAN, 2010) meanwhile little publication investigating this condition in general and lives of autistic children' families in particular ( $\mathrm{Vu}, 2014)$. Henceforth, scholars argue to do much more research to get better understanding on this field in both non-Western nations and in low resources societies (Grinker 2007).

With the hope to learn more about life of these Vietnamese families, the study focused on considering obstacles that the parents experienced when bringing their children to the psychology department. As a result, different themes emerged thanks to stories shared through in-depth interviews.

\section{RESEARCH METHODS}

This study used Interpretative Phenomenological Analysis (IPA) of the qualitative research to give a detail description to particular persons' experiences and to expose how they construct their own viewpoint about lives (Smith \& Eatough, 2007). In an IPA research, 
three significant parts to establish concepts and debates are phenomenology, hermeneutics, and ideography (Smith et al., 1997). Thus, researchers connect experiences and describe phenomenon through participants' perceptions to realize the basic meanings beneath the phenomenon shown by the participants (Baker et al., 1992).

\section{Participants}

Participants in this study consisted of 5 fathers and 3 mothers whose children had been diagnosed with autism. Their personal information is shown in Table 1 . They all have been living in Binh Thuan, a small province of Vietnam without any psychology departments, and is about $200 \mathrm{~km}$ far from Ho Chi Minh city, which has some clinics for autism. A preinterview had been conducted to select parents before the in-depth interviews. Because the purpose of interpretative phenomenological studies is to scrutinize experiences of a certain group related to the phenomenon (Smith \& Osborn, 2003), the "purposeful sampling" method was used to choose a homogeneous group in this study.

\section{Ethical considerations}

A participant information sheet and an informed consent form had been given to parents before they joined the study. They were advised to participate voluntarily and could stop at any time without penalty. To make sure participation confidentiality, pseudonyms were used for participants and proper names, codes were given to interviews and participants.

To explore deeply the journey with numerous sides concerned about taking children to the psychological examination, the study applied the sections "life challenge" and "personal ideology" in "Life Story Interview" list developed by McAdams (1995) which brought a clear look at parents' most difficult obstacles and their solutions as well as their wishes concerned about autism diagnosis. I just started to record 60-minute interviews when being agreed by parents.

All 8 transcribed interviews were analyzed using the IPA data analysis steps developed by Smith, Jarman, and Osborn (1999) and MAXQDA 12 software program, which assisted in creating and linking themes with its recall feature.

First, what participants told was divided into units of meaning and initial notes were transformed into themes after reading transcripts again and again carefully at different times (Smith, Jarman, \& Osborn, 1999). Second, themes were linked through identifying their relations. Each case began to be scrutinized by analyzing each transcript with an interpretive process. Third, main themes were also combined from all cases. New themes emerged in subsequent interviews were checked against earlier transcripts and were modified. Finally, themes were translated into a narrative account and described thoroughly (Smith, Jarman, \& Osborn, 1999). Furthermore, the validity and reliability was ensured through an expert review.

\section{RESULT AND DISCUSSION}

The stories of all participants revolved around what happened when the first time they took their children to another city for the first medical visit because they were the most memorable moments for them. Their hard journey when taking children to the psychological consultation room revealed gradually through difficulties shared by parents that were grouped into the following themes and direct quotations. It was true that getting the children diagnosed is a stressful process for many parents (Howlin \& Moorf, 1997).

\section{Theme 1: Financial problems}


"It is undeniable that money is a painful matter when determining to take the child to another city for diagnosis."

Most parents in this study had to collect money from many sources so that they could afford to take their children to the clinicians. Expenses were centralized for transportation, food and medical consultation.

In fact, when taking care of the children with ASD, families often encounter economic burdens (Giallo, Wood et al., 2013). Additionally, family income reduces for the reason that parent has to resign the jobs to help the children (Altiere and von Kluge, 2009). In Vietnam, political and economic supports to minimize the complications of parents in accessing services for their autistic children have been limited ( $\mathrm{Vu}, 2014)$. Thus, these families are solely in charge of paying for all services, although the health insurance law in Vietnam points out that children under six can take free examination and treatment (National Assembly 2008); however, this does not include children with ASD. All children diagnosed with ASD in this study have not received any social welfare or economic support from the government.

In terms of transport, parents spent a big amount of money for the extra expense. Because the children refused to sit in the coach with many other passengers when the coach was about to start, in order to keep up with the scheduled time for medical examination, the parents took their children down from the coach and rented a private car (Cases B \& E). In cases A, D, and F, everything seemed to be less stressful. Because of anticipating their children's ability to endure in cramped spaces, the parents rented a private car for their journey. However, there were parents experiencing harder moments. Their children did not react negatively to the coach at the first minutes, but after moving about one third of the way, they reacted so violently that the driver, driving assistants and passengers could not stand it. In this situation, parents could do nothing except for taking their children down and took a taxi to continue their journey (Cases $\mathrm{C} \& \mathrm{G}$ ). In case $\mathrm{H}$, parents already bought a ticket but when getting in the coach, the child ran down in high worry and stress. Parents could not get the child into the coach again, so they had to change their plan immediately by buying train tickets to arrive in the city on time.

Thus, it was clear that in the economic situation that was not abundant of teachers, workers, and housewives, the parents had to suffer from big additional expenses for transport.

Besides, parents had to spend a lot on food and beverage for children. Knowing that it would be hard for their children to accept strange dishes on the way, most of the parents prepared carefully what their children often enjoy daily. However, many children in this study threw or hit the food and drinks instead of eating them. A father said "I think that she was too tired and strained. I did not know what to do at that time but being afraid of she was hungry". Gray (1994) also argued how stressful parents are with poor eating habit and behaviors of autistic children. In case $\mathrm{H}$, the child ran suddenly to get a lot of food on the train-food cart and he ate greedily one after another, while the parents of other children ordered many dishes in a small restaurant until their children could eat something (Cases A $\&$ E). "Food and drinks sold on the way or in the city were so expensive, but when the child could not eat anything, it was my constant source of my worry", a mother claimed.

Regarding to the cost for psychological consultation, the health insurance bought by parents for their children in the hometown was invalid because their children came from another province. Furthermore, autism is the syndrome that has not been in the insurance list in Vietnam. Thus, no financial support has been made by the government, all examination expenses must be paid by the parents. 
It was admitted that the sum of money to spend was a quite large amount compared to the monthly income of common employees in Vietnam.

\section{Theme 2: Tiredness}

"Being exhausted, I just wanted to take a deep sleep"

"At 5 a.m., I hugged my child and sat in the line of people waiting for the examination registration number at the Psychology Department. We departed at 2 a.m. to be able to reach Ho Chi Minh City in time for diagnosis in the morning. My sleepy child collapsed on my shoulder. My wife was so enervated to help our child. At 6 a.m., being on my last legs, I got the examination number from the hospital staff'

To gain services for their children, parents spend massive physical efforts (Hutton and Caron, 2005). During the journey, both the parents and children were fatigued. In order to arrive in the city for the morning examination, the parents must leave their home around 2 a.m. In the course of time before that, they could not sleep due to anxiety meanwhile in the car or the train; they were even more difficult to take a nap owning to the fact that they must keep their eyes on the children. Fathers and most mothers were car sick due to exhaustion in previous days. "I vomited, while my child was worn-out and nervous". In case $\mathrm{H}$, father said "The child was less stressful on the train because he could move among the railway wagons but I was really drained of all my energy when following him".

Besides, the children were just as weary as their parents. Being picked up and put in the coach while sleeping, the children were irritable, angry and grimaced. Because they could not call their sleep again easily, they became more exhausted. In other cases, after long time of waiting, the examination day finally came, however, the children got sick. The parents admitted that normally, their children were very susceptible to illness. Being afraid of missing the medical appointment, parents decided not to give cancellation and brought medicine with children for them to take on the way (Cases D \& F). Parents had to accept this fact and had no choice. In Vietnam, the number of public institutes supplying diagnosis services for children with ASD is really limited and they are often built in the two largest cities (CLAN 2010). So, when suspecting autism, parents could only take their children to the big city for a medical examination.

\section{Theme 3: Unexpected behaviors of the children}

"She showed some unconscious behaviors clearly every day, but when traveling a long way and coming to an unfamiliar environment, these behaviors seemed to arise, lasted longer and stronger."

When autistic children are small, parents are able to deal with their aggressive behaviors; nonetheless, this turns into harder when the time goes by (Hutton and Caron 2005). In this study, undergoing a variety of changes in daily activities, the children behaved unexpectedly during the journey, when waiting for the consultation turn, and in the clinic.

The parents supposed that although they chose the most convenient means of transport and even changed it along the way, their children did not cooperate and expressed their high stress. They just screamed, hit the car seats, and hurt their parents and themselves. Hardly did they sleep soundly but required unreasonable things. Only in case H, the child was satisfied with going through the train passenger carriages to enjoy himself and in case A, the child was almost more obedient in the cuddle of his mother.

Even though most children are against traveling, parents did their big shot to take their children to the clinic. Sitting at the waiting chair in front of the psychology clinic, parents took turns observing carefully their child, counted every minute for their children's 
diagnosis turn. Most of the children could sit still in just some minutes. They only wanted to do what they liked such as moving around (Cases B, C \& H), drawing the curtains to the left, then to the right to make noise (Case D).

The rest of the children made their parents more extremely anxious as they banged the chairs or walls with their heads, screamed, laughed and cried without consciousness.

Furthermore, parents experienced awkward instants in the clinic. Two of the children were uncomfortable in diapers that their parents were reluctant to wear for them before entering the clinic, because they did not usually wear these things at home. When the children get distracted with the nappies, the clinician advised their parents to remove the diapers so that the children could pay their attention to interact with the clinician. However, it was so annoying because as soon as parents took off the diapers, the children urinated, then the cleaner was called to come and clean (Cases F \& B).

Some other children obeyed the clinician to stack blocks of wood, but after a few minutes they collapsed the piles angrily or threw many pieces of wood away (Cases A, C, \& E). Besides, two children who were allowed to go around the consultation room freely with some intervention equipment by the clinician smashed some items in the very fast way (Cases D \& H).

In short, the parents loved their children with their high responsibility; however, it was the fact that the children's challenging behaviors caused many problems for their beloved parents.

\section{CONCLUSION}

While there has been an increase in the number of children diagnosed with ASD in Vietnam (Yen 2010), many personal opinions posted in the media expose that these parents fight in despair with the diagnostic process ( $\mathrm{Vu}, 2014)$. In spite of such many difficulties, parents did not stop finding ways for their children to access medical services. This paper investigating obstacles that Vietnamese parents with autistic children met on the way to see clinicians. With this study, the author wishes to partly broaden the society's understanding on this field and convey parents' dreams related to diagnosis in Vietnam.

"I hope that autism clinics in public hospitals would be built in small provinces to reduce our difficulties when traveling, health insurance would be able to be used in autism examination to reduce the high cost", "There would be many good experts in this field to reduce waiting time for examination", and "In the near future, parents and children living in small provinces could get diagnosis at the hometown instead of going to the big cities with so many difficulties". These dreams will come true when the whole society join hands to solve this problem.

\section{REFERENCES}

Altiere, M. J., \& Von Kluge, S. (2009). Searching for acceptance: Challenges encountred while rasing a child with autism. Journal of Intellectual \& Developmental Disability.

American Psychiatric Association. (2013). Diagnostic and Statistical Manual of Mental Disorders, 5th Edition. Arlington, VA American Psychiatric Association, Web. access date: 1 June 2013. dsm.psychiatryonline.org

Baker, C., Wuest, J., \& Stern, P. N. (1992). Method slurring: The grounded theory/ phenomenology example. Journal of Advanced Nursing.

CLAN. (2010). Children's Hospital 1: Autism Project Report: Carings and living as neighbours (CLAN).

Faja S, Dawson G. (2006). Early Intervention for Autism. Handbook of preschool mental health: Development, disorders, and treatment. New York City: Guilford Press. 
Giallo, R., Wood, C. E., Jellett, R., \& Porter, R. (2013). Fatigue, wellbeing and parental self-efficacy in mothers of children with an Autism Spectrum Disorder. Autism.

Gray, D. E. (1994). Coping with autism: stresses and strategies. Sociology of Health \& Illness.

Grinker, R. R. (2007). Unstrange Minds: Remapping the World of Autism Basic Books.

Howlin, P., Goode, S., Hutton, J., \& Rutter, M. (2004). Adult outcome for children with autism. Journal of Child Psychology and Psychiatry, 45(2), 212-229.

Howlin, P., \& Moore, A. (1997). Diagnosis in autism: A survey of over 1200 patients in the UK. Autism: International Journal of Research and Practice. Retrieved from http://dx.doi.org/10.1177/1362361397012003

Hutton, A. M., \& Caron, S. L. (2005). Experiences of Families With Children With Autism in Rural New England. Focus on Autism and Other Developmental Disabilities.

McAdams, D. P. (1995). The life story interview. Northwestern University, Foley Center for the Study of Lives. http://www.sesp.northwestern.edu/foley/instruments/interview/

National Assembly. (2008). Luật bảo hiểm y tế. (Law on medical insurance). Hanoi.

Neely-Barnes, S. L., Hall, H. R., Roberts, R. J., \& Graff, J. C. (2011). Parenting a child with an autism spectrum disorder: Public perceptions and parental conceptualization. Journal of Family Social Work.

Phelps, K. W., Hodgson, J. L., McCammon, S. L., \& Lamson, A. L. (2009). Caring for an individual with autism disorder: a qualitative analysis. J Intellect Dev Disabil.

Singer, A. (Producer). (2010). Parental perspectives and supporting families. Autism and Related Disorders: CHLD 350a/PSYC350. Retrieved from http://autism.yale.edu/

Smith, J. A., \& Eatough, V. (2007). Interpretative phenomenological analysis. In E. Lyons \& A. Coyle (Eds.), Analysing qualitative data in psychology: A practical \& comparative guide (pp. 35-50). London: Sage.

Smith, J. A., Flowers, P., \& Osborn, M. (1997). Interpretative phenomenological analysis and the psychology of health and illness. Material discourses of health and illness.

Smith, J. A., Jarman, M., \& Osborn, M. (1999). Doing interpretative phenomenological analysis. In E. Dans, M. Murray, \& K. Chamberlain (Eds.), Qualitative health psychology: Theories and methods (pp. 218-240). London: Sage.

Smith, J. A., \& Osborn, M. (2003). Interpretative phenomenological analysis. In J. A. Smith (Eds.), Qualitative psychology: A practical guide to research methods (pp. 5180). London: Sage.

Vu, S. H (2014). Understanding autism spectrum disorder in Hanoi, Vietnam. (PhD thesis), The University of Queensland, Brisbane, QLD.

Yen, N. T. H. (2010). Research with families having children with disability in East Asia. Hanoi: Faculty of Special Education, Hanoi National University of Education 